JAMA | Original Investigation

\title{
Effect of Filgotinib vs Placebo on Clinical Response in Patients With Moderate to Severe Rheumatoid Arthritis Refractory to Disease-Modifying Antirheumatic Drug Therapy The FINCH 2 Randomized Clinical Trial
}

Mark C. Genovese, MD; Kenneth Kalunian, MD; Jacques-Eric Gottenberg, MD, PhD; Neelufar Mozaffarian, MD, PhD; Beatrix Bartok, MD; Franziska Matzkies, MD; Jie Gao, PhD; Ying Guo, PhD; Chantal Tasset, PhD; John S. Sundy, MD, PhD; Kurt de Vlam, MD, PhD;

David Walker, MD; Tsutomu Takeuchi, MD, PhD

IMPORTANCE Patients with active rheumatoid arthritis (RA) despite treatment with biologic disease-modifying antirheumatic drug (bDMARD) therapy need treatment options.

OBJECTIVE To evaluate the effects of filgotinib vs placebo on the signs and symptoms of RA in a treatment-refractory population.

DESIGN, SETTING, AND PARTICIPANTS A 24-week, randomized, placebo-controlled, multinational phase 3 trial conducted from July 2016 to June 2018 at 114 sites internationally, randomizing 449 adult patients (and treating 448) with moderately to severely active RA and inadequate response/intolerance to 1 or more prior bDMARDs.

INTERVENTIONS Filgotinib, $200 \mathrm{mg}(\mathrm{n}=148)$; filgotinib, $100 \mathrm{mg}(\mathrm{n}=153)$; or placebo $(\mathrm{n}=148)$ once daily; patients continued concomitant stable conventional synthetic DMARDs (csDMARDs).

MAIN OUTCOMES AND MEASURES The primary end point was the proportion of patients who achieved $20 \%$ improvement in the American College of Rheumatology criteria (ACR2O) at week 12 . Secondary outcomes included week 12 assessments of low disease activity (disease activity score in 28 joints-C-reactive protein [DAS28-CRP] $\leq 3.2$ ) and change in Health Assessment Questionnaire-Disability Index, 36-Item Short-Form Health Survey Physical Component, and Functional Assessment of Chronic Illness Therapy-Fatigue scores, as well as week 24 assessment of remission (DAS28-CRP <2.6) and adverse events.

RESULTS Among 448 patients who were treated (mean [SD] age, 56 [12] years; 360 women [80.4\%]; mean [SD] DAS28-CRP score, 5.9 [0.96]; 105 [23.4\%] with $\geq 3$ prior bDMARDs), 381 (85\%) completed the study. At week 12, more patients receiving filgotinib, $200 \mathrm{mg}$ (66.0\%) or $100 \mathrm{mg}$ (57.5\%), achieved ACR2O response (placebo, 31.1\%; difference vs placebo: $34.9 \%$ [95\% Cl, 23.5\%-46.3\%] and $26.4 \%$ [95\% Cl, 15.0\%-37.9\%], respectively; both $P<.001$ ), including among patients with prior exposure to 3 or more bDMARDs $(70.3 \%, 58.8 \%$, and $17.6 \%$, respectively; difference vs placebo: $52.6 \%$ [95\% Cl, 30.3\%-75.0\%] for filgotinib, $200 \mathrm{mg}$, and $41.2 \%$ [95\% Cl, 17.3\%-65.0\%] for filgotinib, $100 \mathrm{mg}$; both $P<.001$ ). The most common adverse events were nasopharyngitis (10.2\%) for filgotinib, $200 \mathrm{mg}$; headache, nasopharyngitis, and upper respiratory infection (5.9\% each) for filgotinib, $100 \mathrm{mg}$; and RA (6.1\%) for placebo. Four uncomplicated herpes zoster cases and 1 retinal vein occlusion were reported with filgotinib; there were no opportunistic infections, active tuberculosis,

malignancies, gastrointestinal perforations, or deaths.

CONCLUSIONS AND RELEVANCE Among patients with active RA who had an inadequate response or intolerance to 1 or more bDMARDs, filgotinib, $100 \mathrm{mg}$ daily or $200 \mathrm{mg}$ daily, compared with placebo resulted in a significantly greater proportion achieving a clinical response at week 12 . However, further research is needed to assess longer-term efficacy and safety.

TRIAL REGISTRATION ClinicalTrials.gov Identifier: NCT02873936

JAMA. 2019;322(4):315-325. doi:10.1001/jama.2019.9055

Corrected on February 4, 2020
$+$

Visual Abstract

$\leftarrow$

ditorial page 309

Supplemental content

+ CME Quiz at

jamanetwork.com/learning and CME Questions page 359
Author Affiliations: Author affiliations are listed at the end of this article.

Corresponding Author: Mark C. Genovese, MD, Division of Immunology and Rheumatology, Stanford University School of Medicine, 1000 Welch Rd, Ste 203 Palo Alto, CA 94304 (genovese@ stanford.edu). 
$\mathrm{R}$ heumatoid arthritis (RA) is a systemic autoimmune disease characterized by chronic inflammation, leading to destruction and deformity of joints, disability, and decreased quality of life. Treatment is guided by disease severity and the patient's comorbidities and response to therapy. Pharmacotherapy typically begins with a conventional synthetic disease-modifying antirheumatic drug (csDMARD), such as methotrexate, often plus a short course of glucocorticoids. If response to initial therapy is inadequate, addition of a targeted therapy, either a biologic bDMARD or a targeted synthetic DMARD, such as Janus kinase (JAK)-signal transducer and activator of transcription inhibitors, is the next step. ${ }^{1,2}$ The first targeted therapy is often a tumor necrosis factor (TNF) inhibitor; however, patients often discontinue TNF inhibitors due to ineffectiveness and adverse events (AEs). ${ }^{3}$ In this setting, treatment guidelines recommend switching to another TNF inhibitor, to a bDMARD with alternative mechanism of action, or to a targeted synthetic DMARD. ${ }^{1,2}$

While the cause of RA is not completely understood, various factors have been implicated in its pathogenesis, including several prominent cytokine pathways. JAK inhibitors block the signaling of multiple cytokines, growth factors, and hormones implicated in autoimmunity. ${ }^{4} \mathrm{JAK}$ inhibition may, therefore, have potential as a therapeutic option for a range of inflammatory conditions including RA. 5,6 Filgotinib is an oral, small-molecule inhibitor of JAK1 that has demonstrated clinical efficacy, both as a monotherapy and in combination with methotrexate, in phase 2 studies in patients with moderately to severely active RA. ${ }^{7-9}$ The multinational, phase 3 FINCH 2 study compared the effects of filgotinib vs placebo for the treatment of patients with moderately to severely active RA and an inadequate response or intolerance to 1 or more prior bDMARDs.

\section{Methods}

\section{Study Design}

This was a randomized, double-blind, placebo-controlled study conducted between July 2016 and June 2018 at 114 sites (hospitals, outpatient clinics, academic centers, and private research sites) internationally. The protocol and statistical analysis plan are included in Supplement 1 and Supplement 2, respectively. The trial was conducted in accordance with the Declaration of Helsinki and the International Council for Harmonisation Good Clinical Practice guidelines and approved by each study center's institutional review board or ethics committee. All patients provided written informed consent.

Patients were 18 years of age or older at the time of consent with a diagnosis of RA, ${ }^{10} 6$ or more swollen joints (swollen joint count [SJC] of 66 joints [SJC66]), and 6 or more tender joints (tender joint count [TJC] of 68 joints [TJC68]) at both screening and baseline, and a serum C-reactive protein (CRP) level of $4 \mathrm{mg} / \mathrm{L}$ or greater based on central laboratory assessment at screening. Self-reported patient race and ethnicity (predefined categories) were collected to meet regulatory

\section{Key Points}

Question Is filgotinib more effective than placebo in active rheumatoid arthritis refractory to biologic disease-modifying antirheumatic drug therapy?

Findings In this randomized clinical trial of 448 patients with active rheumatoid arthritis who had an inadequate response or intolerance to 1 or more biologic disease-modifying antirheumatic drugs, clinical response as measured by American College of Rheumatology $20 \%$ response was achieved at week 12 by significantly greater proportions of patients treated with filgotinib, $200 \mathrm{mg}(66.0 \%)$ or $100 \mathrm{mg}$ (57.5\%), compared with placebo (31.1\%).

Meaning A greater proportion of patients who received filgotinib, compared with those who received placebo, achieved clinical response at 12 weeks, but further research is needed to assess longer-term efficacy and safety.

requirements. Patients had active RA despite ongoing treatment with csDMARDs and an inadequate response or intolerance to 1 or more prior bDMARDs. All bDMARDs were discontinued 4 or more weeks ( $\geq 6$ months for B-cell-depleting bDMARDs) prior to randomization. Patients with evidence of latent tuberculosis could enroll only if appropriate prophylaxis was initiated prior to first dose of study drugs. Main exclusion criteria included previous treatment with a JAK inhibitor, specified abnormal laboratory results, pregnancy, and/or recent or active infection.

\section{Randomization}

Patients were randomized via an interactive web response system in a 1:1:1 ratio to once-daily filgotinib, $200 \mathrm{mg}$; filgotinib, $100 \mathrm{mg}$; or placebo tablets (matched in appearance) using a stratified randomization schedule with a block size of 6 . The randomization sequence was prepared by an independent statistician; patients were stratified by geographic region, prior exposure to bDMARDs ( $<3$ or $\geq 3$ ), and seropositivity (rheumatoid factor or anticyclic citrullinated peptide antibodies) at screening. Study treatment allocation was determined by an interactive web response system.

\section{Interventions}

All patients assigned to once-daily filgotinib, $200 \mathrm{mg}$; filgotinib, $100 \mathrm{mg}$; or placebo continued 1 to 2 protocol-specified stable csDMARDs (methotrexate, hydroxychloroquine, sulfasalazine, or leflunomide; methotrexate and leflunomide were not permitted in combination), and dose decreases were permitted only for intolerance/AE and/or laboratory abnormalities but not for change in disease activity. Stable doses of glucocorticoids ( $\leq 10 \mathrm{mg} / \mathrm{d}$ prednisone or equivalent) and/or nonsteroidal anti-inflammatory drugs were permitted. Patients who discontinued study drug for any reason, including those who had not achieved responder status (defined as $\geq 20 \%$ improvement in both SJC66 and TJC68 from day 1 to week 14), were allowed to continue study visits and assessments while receiving standard-of-care therapy (investigator's choice of treatment appropriate for the patient). All patients who attained responder status at week 14 continued 
their assigned study drugs in blinded fashion through week 24. Clinical assessments, patient questionnaires, collection of AEs (coded according to Medical Dictionary for Regulatory Activities version 21.0 and using Common Terminology Criteria for Adverse Events version 4.03 criteria), and laboratory tests were performed on day 1 and weeks $2,4,8,12,14,16$, 20 , and 24 (or early termination) to evaluate efficacy and AEs according to the prespecified analysis. Uncomplicated herpes zoster cases limited to the primary dermatome or 2 adjacent dermatomes were not considered opportunistic infections. For patients discontinuing the study, a postdosing visit occurred 4 weeks after the last dose of study drug.

\section{Outcomes}

The primary end point was the proportion of patients with an American College of Rheumatology 20\% (ACR20) response at week 12 . Key secondary efficacy end points were the change from baseline in Health Assessment QuestionnaireDisability Index (HAQ-DI) score, the proportion of patients with disease activity score in 28 joints count using CRP (DAS28-CRP) of 3.2 or less, and the change from baseline in the 36-Item Short-Form Health Survey Physical Component and Functional Assessment of Chronic Illness TherapyFatigue scores measured at week 12, as well as the proportion of patients with DAS28-CRP less than 2.6 at week 24. Other secondary end points included ACR50 and ACR70 responses and patient's and physician's global assessments of disease. ACR20, ACR50, and ACR70 response rates are based on patients achieving $20 \%$ or more, $50 \%$ or more, and $70 \%$ or more improvement in TJC68 and SJC66 and 20\% or more, 50\% or more, or $70 \%$ or more improvement in at least 3 of 5 ACR core set measures (patient's pain, patient's global assessment of disease activity, physician's global assessment of disease activity, physical function, and highly sensitive quantification of CRP concentration). ${ }^{11}$ SJC66 and TJC68 are counts of swollen and tender joints evaluating a fixed set of 66 and 68 joints, respectively, from both upper and lower body and hands and feet; SJC28 and TJC28 are abbreviated assessments considering a subset of only 28 joints. Patient's pain, patient's global assessment of disease activity, and physician's global assessment of disease activity are measured on 0- to 100-mm visual analog scales, with higher scores representing worse pain or disease. DAS28-CRP is another composite disease activity score factoring in TJC28, SJC28, and CRP levels and a physician's global assessment, and is scored on a range up to 10.0, with scores of 3.2 or lower considered low disease activity and scores less than 2.6 considered remission. ${ }^{12,13}$

The HAQ-DI assesses 8 functional categories (dressing and grooming, arising, eating, walking, hygiene, reach, grip, and other activities), with scores ranging from $\mathrm{O}$ (no disability) to 3 (completely disabled), and a change of 0.22 considered the minimally important difference. ${ }^{14,15}$ The Short-Form Health Survey is composed of 36 items that group into 8 scales, which can be further summarized as Physical and Mental Component scores; scores range from 0 to 100, representing "least health" to "greatest health."16 The Functional Assessment of Chronic Illness Therapy-Fatigue is a 13-item questionnaire on fatigue during a patient's usual daily activities over the past week that is scored from 0 to 52, with higher scores indicating less fatigue. ${ }^{17}$

The Clinical Disease Activity Index and Simplified Disease Activity Index are both composite scores based on TJC28, SJC28, patient's global assessment, and physician's global assessment; the Simplified Disease Activity Index also includes CRP. ${ }^{18-20}$ The Clinical Disease Activity Index is scored on a scale of 0 to 76 , with higher scores indicating greater disease activity and a score of 10 or lower indicating low disease activity. The Simplified Disease Activity Index is scored on a scale of 0 to 86.0, with higher scores indicating greater disease activity and a score of 11 or lower indicating low disease activity. Other outcomes assessed but not reported herein included ACR-N and European League Against Rheumatism responses, as well as Work Productivity and Activity Impairment Questionnaire for Rheumatoid Arthritis and European Quality of Life-5 Dimensions scores.

\section{Statistical Analysis}

The key secondary end point, HAQ-DI, required a bigger sample size to ensure adequate power and was used to determine sample size. A sample size of 141 patients in each group (423 total) was targeted to provide $90 \%$ power at a 2 -sided .05 level to detect a difference of 0.25 between filgotinib and placebo on the change from baseline in HAQ-DI at week 12 and to provide more than 90\% power to detect an increase in ACR20 response rate of $25 \%$ to $45 \%$ between placebo and filgotinib groups.

The primary and key secondary end points were tested according to the hierarchical testing principle (as described in eFigure 1 in Supplement 3) at the 2-sided .05 level to maintain control of type I error. The primary analyses consist of a superiority test of filgotinib, $200 \mathrm{mg}$, compared with placebo based on the ACR2O response rate at week 12. The hypothesis testing for secondary analyses commenced if the primary analysis reached statistical significance and were tested according to the hierarchical testing principle at the 2-sided .05 level. If a null hypothesis was not rejected, formal sequential testing was to be stopped and only nominal significance was to be reported for the remaining hypotheses.

The full analysis set includes all randomized patients who received at least 1 dose of study drug, and this set was used for efficacy analyses. Comparison of filgotinib vs placebo was made by logistic regression with treatment and stratification factors (geographic region, prior exposure to number of bDMARDs, and presence of rheumatoid factor or anticyclic citrullinated peptide antibody at screening) included in the model with nonresponder imputation for ACR response rate and other binary end points. Patients with missing binary end points were considered to be nonresponders (ie, nonresponder imputation). The $P$ value from the logistic regression model is reported. A mixed-effects model with repeated measures that included all available data was used to evaluate treatment effect for continuous end points with baseline value, stratification factors (geographic region, prior exposure to number of bDMARDs, and presence of rheumatoid factor or anticyclic citrullinated peptide antibody at screening), treatment, visit, and treatment by visit interaction included as fixed effects and time being a random effect. Treatment comparison 


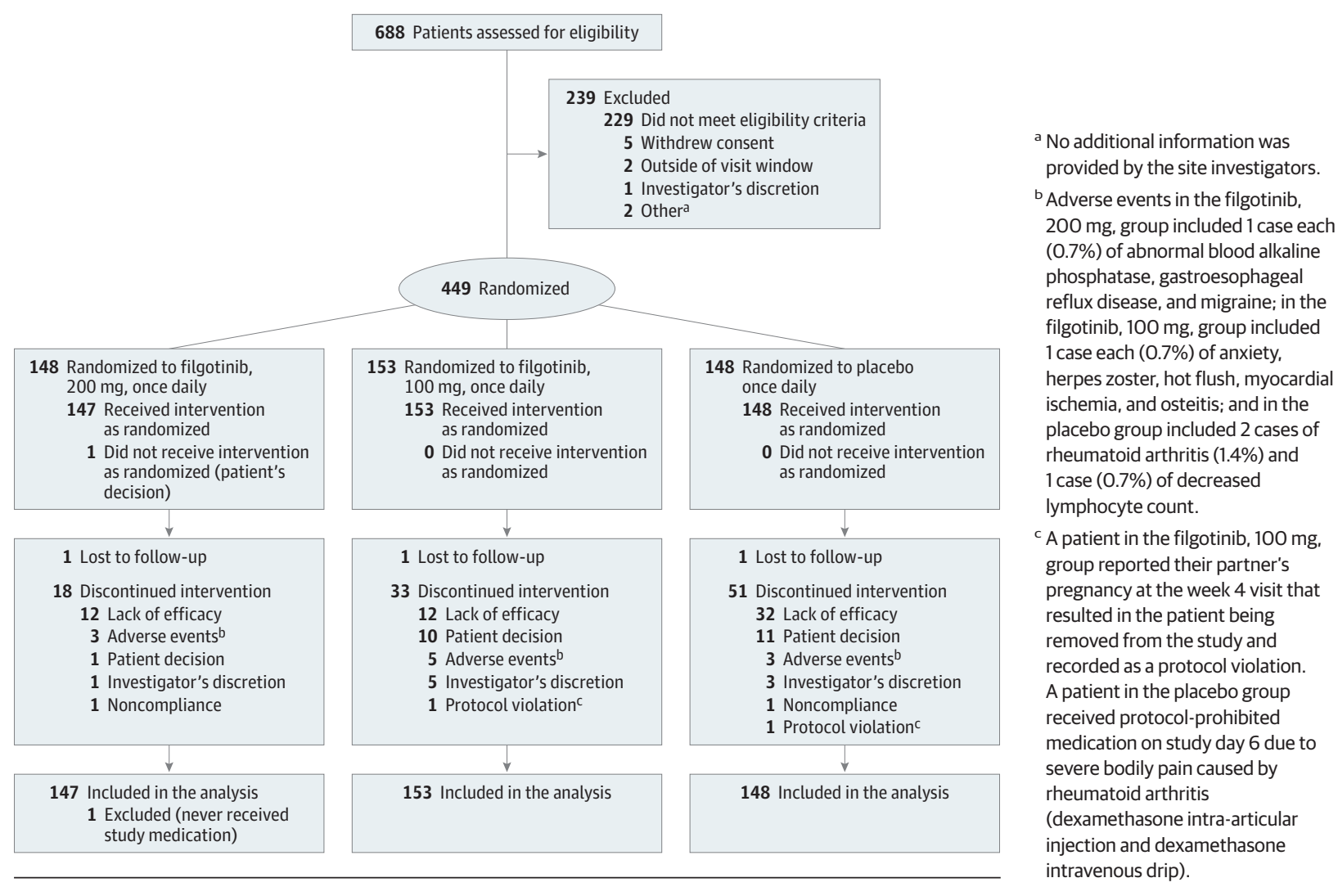

on the other secondary end points was not adjusted for multiplicity, and nominal $P$ values are presented and should be interpreted as exploratory.

Sensitivity analyses (eg, multiple imputation and tipping point analyses) were conducted to ensure that conclusions were robust and not dependent on mechanisms used to account for missing data. The multiple imputation procedure replaced each missing value with a set of plausible values that represented the uncertainty about the right value to impute. Fifty imputed data sets were generated based on logistic regression models for binary efficacy end points (eg, ACR20) or linear regression models for continuous efficacy end points (HAQ-DI). These multiple imputed data sets were analyzed using the same method as for the primary analysis. The results from each set of imputed data sets were combined using Rubin's rule. The stratification factors were included in the imputation model as covariates, and all available data at postbaseline visits up to the time point of interest were included in the longitudinal model. A $\delta$-adjusting pattern-mixture approach for tipping point analysis was conducted for the primary and key secondary efficacy end points to assess the robustness of analysis results under missing not at random assumption. Specifically, a series of analyses were performed with a range of different values of the shift parameter $\delta$ applied to the imputed data sets at which the conclusion about the statistical significance of the estimated treatment effect will be altered. Each $\delta$ value is classified as either "altering the study's conclusion" or tips from "keeping the study's conclusion unchanged.” For each $\delta$ value, multiple imputed data sets were generated. The same analysis method as for the primary analysis was applied when analyzing adjusted data generated under the different $\delta$ values. All statistical analyses were done using SAS version 9.4 (SAS Institute).

Subgroup analyses were performed by repeating the analysis within subgroups of patients defined by a subgrouping variable. There was no formal testing for interactions, so effect sizes among subgroups should not be compared.

\section{Results}

\section{Study Participants}

The disposition of the 688 screened patients is shown in Figure 1. Table 1 shows baseline characteristics and eTable 1 in Supplement 3 shows prior bDMARD and concurrent methotrexate and steroid use. Most patients (81.9\%) were receiving concomitant methotrexate on the first dosing date and the mean (SD) dose was 15.8 (5.25) mg/week (eTable 1 in Supplement 3). Most of the enrolled patients were from the United States (255 patients; 56.9\%) and Europe (103; 23.0\%) (eFigure 2 in Supplement 3). Selected baseline characteristics within each region are in eTable 2 in Supplement 3.

Patients who did not attain a $20 \%$ or greater decrease in both SJC and TJC at week 14 were to transition to a standardof-care group. The numbers of nonresponders at week 14 were 


\begin{tabular}{|c|c|c|c|}
\hline \multirow[b]{2}{*}{ Characteristic } & \multicolumn{3}{|l|}{ №. (\%) } \\
\hline & $\begin{array}{l}\text { Filgotinib, } 200 \mathrm{mg}, \\
\text { Once Daily } \\
(\mathrm{n}=147)\end{array}$ & $\begin{array}{l}\text { Filgotinib, } \\
100 \mathrm{mg}, \text { Once Daily } \\
(\mathrm{n}=153)\end{array}$ & $\begin{array}{l}\text { Placebo } \\
\text { Once Daily } \\
(\mathrm{n}=148)\end{array}$ \\
\hline Age, mean (SD), y & $56(12.5)$ & $55(12.0)$ & $56(12.1)$ \\
\hline$<65$ & $112(76.2)$ & $117(76.5)$ & $106(71.6)$ \\
\hline$\geq 65$ & $35(23.8)$ & $36(23.5)$ & $42(28.4)$ \\
\hline \multicolumn{4}{|l|}{ Sex } \\
\hline Male & $27(18.4)$ & $34(22.2)$ & $27(18.2)$ \\
\hline Female & $120(81.6)$ & $119(77.8)$ & $121(81.8)$ \\
\hline \multicolumn{4}{|l|}{ Race/ethnicity } \\
\hline White & $110(74.8)$ & $109(71.2)$ & $97(65.5)$ \\
\hline Asian & $15(10.2)$ & $20(13.1)$ & $15(10.1)$ \\
\hline Black/African American & $14(9.5)$ & $12(7.8)$ & $21(14.2)$ \\
\hline American Indian/Alaska Native & $7(4.8)$ & $9(5.9)$ & $10(6.8)$ \\
\hline Other $^{\mathrm{a}}$ & $1(0.7)$ & $3(2.0)$ & $2(1.4)$ \\
\hline Not permitted ${ }^{a}$ & 0 & 0 & $3(2.0)$ \\
\hline \multicolumn{4}{|l|}{ Geographic region ${ }^{\mathrm{b}}$} \\
\hline Region A & $111(75.5)$ & 110 (71.9) & $110(74.3)$ \\
\hline Region B & $12(8.2)$ & $12(7.8)$ & $11(7.4)$ \\
\hline Region D & $12(8.2)$ & $16(10.5)$ & $14(9.5)$ \\
\hline Region $\mathrm{E}$ & $12(8.2)$ & $15(9.8)$ & $13(8.8)$ \\
\hline Body mass index, median $(I Q R)^{c}$ & $29.4(24.2-35.1)$ & $28.7(25.2-34.2)$ & $28.8(24.6-33.7)$ \\
\hline $\begin{array}{l}\text { Duration of rheumatoid arthritis diagnosis, } \\
\text { median (IQR), y }\end{array}$ & $9.8(5.2-19.6)$ & $10.3(6.4-16.4)$ & $9.9(5.2-17.2)$ \\
\hline High-sensitivity CRP median (IQR), mg/L & $11.2(5.7-22.9)$ & $10.6(5.5-23.8)$ & $9.7(5.3-20.0)$ \\
\hline Presence of RF only & $13(8.8)$ & $5(3.3)$ & $8(5.4$ \\
\hline Presence of anti-CCP antibody only & $8(5.4)$ & $11(7.2)$ & $11(7.4)$ \\
\hline Presence of RF + anti-CCP antibody & $91(61.9)$ & $102(66.7)$ & $84(56.8)$ \\
\hline \multicolumn{4}{|l|}{ No. of prior biologic DMARD exposures } \\
\hline$<3$ & $110(74.8)$ & $119(77.8)$ & $114(77.0)$ \\
\hline$\geq 3$ & $37(25.2)$ & $34(22.2)$ & $34(23.0)$ \\
\hline \multicolumn{4}{|l|}{$\begin{array}{l}\text { Reason for failure of prior biologic } \\
\text { DMARD exposures }\end{array}$} \\
\hline Lack of efficacy & $125(85.0)$ & $129(84.3)$ & $126(85.1)$ \\
\hline Intolerance & $36(24.5)$ & $34(22.2)$ & $32(21.6)$ \\
\hline HAQ-DI, mean (SD) ${ }^{d}$ & $1.70(0.7)$ & $1.64(0.7)$ & $1.65(0.6)$ \\
\hline SJC66, mean (SD) ${ }^{\mathrm{d}}$ & $18(12.5)$ & $17(12.4)$ & $17(9.7)$ \\
\hline TJC68, mean (SD) ${ }^{\mathrm{d}}$ & $28(16.1)$ & $26(15.4)$ & $27(15.5)$ \\
\hline SJC28, mean $(S D)^{d}$ & $12(6.3)$ & $12(6.0)$ & $12(6.0)$ \\
\hline TJC28, mean $(S D)^{d}$ & $16(7.7)$ & $15(6.8)$ & $16(6.9)$ \\
\hline DAS28-CRP, mean (SD) ${ }^{\mathrm{d}}$ & $5.9(1.03)$ & $5.9(0.98)$ & $5.9(0.86)$ \\
\hline $\begin{array}{l}\text { Functional Assessment of Chronic Illness } \\
\text { Therapy-Fatigue, mean (SD) })^{\mathrm{d}}\end{array}$ & $24.2(11.5)$ & $23.7(12.3)$ & $25.4(10.9)$ \\
\hline $\begin{array}{l}\text { Patient's pain assessment, } \\
\text { mean (SD), } \mathrm{mm}^{\mathrm{d}}\end{array}$ & $66(21.6)$ & $67(21.7)$ & $68(19.9)$ \\
\hline \multicolumn{4}{|l|}{$\begin{array}{l}\text { Global assessment of disease activity, } \\
\text { mean (SD), } \mathrm{mm}^{\mathrm{d}}\end{array}$} \\
\hline Patient's & $68(20.6)$ & $69(20.2)$ & $70(18.0)$ \\
\hline Physician's & $69(17.6)$ & $68(18.7)$ & $66(16.7)$ \\
\hline \multicolumn{4}{|l|}{ Disease Activity Index, mean (SD) ${ }^{d}$} \\
\hline Simplified & $43.4(14.64)$ & $42.6(14.16)$ & $43.0(12.33)$ \\
\hline Clinical & $41.7(14.23)$ & $40.4(13.23)$ & $41.4(12.00)$ \\
\hline
\end{tabular}

Abbreviations: CCP, cyclic citrullinated peptide; CRP, C-reactive protein; DAS28-CRP, disease activity score for 28 joints using C-reactive protein; DMARD, disease-modifying antirheumatic drug; HAQ-DI, Health Assessment Questionnaire-Disability Index; IQR, interquartile range: $\mathrm{RF}$, rheumatoid factor; SJC, swollen joint count; TJC, tender joint count.

${ }^{a}$ Other races included people whose predominant origins cannot be determined or who are of mixed race and do not identify with a primary race. Not permitted category includes patients whose local regulators did not allow collection of race or ethnicity information.

${ }^{b}$ Region A: Australia, Belgium, France, Germany, Israel, Republic of Korea, Spain, Switzerland, United Kingdom, and United States. Region B: Hungary and Poland. Region C: China; no patients were screened or enrolled in this region. Region D: Argentina and Mexico. Region E: Japan.

c Calculated as weight in kilograms divided by height in meters squared.

${ }^{d}$ See the Methods section for descriptions of the scale scores.
12 (8.2\%) for filgotinib, $200 \mathrm{mg} ; 14$ (9.2\%) for filgotinib, 100 mg; and 23 (18.2\%) for placebo. Fifteen (10.2\%), 23 (15\%), and $29(19.6 \%)$ patients, respectively, missed the week 14 visit for determination of SJC or TJC, and their responder status was instead evaluated at week 12 or week 16 , as specified in the statistical analysis plan (Supplement 2). 


\begin{tabular}{|c|c|c|c|c|c|c|c|}
\hline & \multicolumn{2}{|l|}{ Filgotinib } & \multirow[b]{2}{*}{ Placebo } & \multicolumn{2}{|l|}{ Difference vs Placebo } & \multicolumn{2}{|c|}{$P$ Value for Filgotinib } \\
\hline & $200 \mathrm{mg}$ & $100 \mathrm{mg}$ & & $200 \mathrm{mg}$ & $100 \mathrm{mg}$ & $200 \mathrm{mg}$ & $100 \mathrm{mg}$ \\
\hline \multicolumn{8}{|l|}{ Week 12} \\
\hline \multicolumn{8}{|l|}{ HAQ-DI } \\
\hline No. & 137 & 140 & 129 & & & & \\
\hline Mean (SD) & $1.15(0.74)$ & $1.15(0.71)$ & $1.40(0.71)$ & & & & \\
\hline $\begin{array}{l}\text { Mean change from } \\
\text { baseline (SD) }\end{array}$ & $-0.55(0.59)$ & $-0.48(0.60)$ & $-0.23(0.55)$ & $-0.32(-0.45 \text { to }-0.19)^{b}$ & $-0.27(-0.40 \text { to }-0.14)^{b}$ & $<.001$ & $<.001$ \\
\hline \multicolumn{8}{|l|}{$\mathrm{HAQ}$-DI reduction $\geq 0.22$} \\
\hline No. (\%) & $144(66.7)$ & $148(66.2)$ & $144(44.4)$ & $22.2(10.3 \text { to } 34.1)^{c}$ & $21.8(10.0 \text { to } 33.6)^{c}$ & $<.001$ & $<.001$ \\
\hline \multicolumn{8}{|l|}{ DAS28-CRP $\leq 3.2$} \\
\hline No. (\%) & $147(40.8)$ & $153(37.3)$ & $148(15.5)$ & $25.3(14.7 \text { to } 35.8)^{c}$ & $21.7(11.4 \text { to } 32.0)^{c}$ & $<.001$ & $<.001$ \\
\hline \multicolumn{8}{|l|}{$\begin{array}{l}\text { 36-Item Short-Form } \\
\text { Health Survey Physical } \\
\text { Component score }\end{array}$} \\
\hline No. & 141 & 144 & 133 & & & & \\
\hline $\begin{array}{l}\text { Mean change from } \\
\text { baseline (SD) }\end{array}$ & $7.6(7.68)$ & $6.8(8.22)$ & $3.6(8.16)$ & $4.3(2.5 \text { to } 6.1)^{b}$ & $7.6(1.6 \text { to } 15.2)^{b}$ & $<.001$ & $<.001$ \\
\hline \multicolumn{8}{|l|}{ DAS28-CRP <2.6 } \\
\hline No. (\%) & $147(22.4)$ & $153(25.5)$ & $148(8.1)$ & $14.3(5.6 \text { to } 23.1)^{c}$ & $17.4(8.5 \text { to } 26.2)^{c}$ & $<.001$ & $<.001$ \\
\hline \multicolumn{8}{|l|}{$\begin{array}{l}\text { Functional Assessment } \\
\text { of Chronic Illness } \\
\text { Therapy-Fatigue }\end{array}$} \\
\hline No. & 140 & 143 & 132 & & & & \\
\hline $\begin{array}{l}\text { Mean change from } \\
\text { baseline (SD) }\end{array}$ & $9.6(11.24)$ & $8.3(10.80)$ & $4.5(10.37)$ & $5.0(1.19)^{d}$ & $3.2(1.18)^{d}$ & $<.001$ & .007 \\
\hline \multicolumn{8}{|l|}{ Week 24} \\
\hline \multicolumn{8}{|l|}{ HAQ-DI } \\
\hline No. & 123 & 113 & 92 & & & & \\
\hline Mean (SD) & $0.95(0.71)$ & $1.04(0.71)$ & $1.22(0.68)$ & & & & \\
\hline $\begin{array}{l}\text { Mean change from } \\
\text { baseline (SD) }\end{array}$ & $-0.75(0.62)$ & $-0.60(0.66)$ & $-0.42(0.60)$ & $-0.36(-0.51 \text { to }-0.21)^{b}$ & $-0.22(-0.37 \text { to }-0.08)^{b}$ & $<.001$ & .003 \\
\hline \multicolumn{8}{|c|}{$\mathrm{HAQ}$-DI reduction $\geq 0.22$} \\
\hline No. (\%) & $144(68.8)$ & $148(54.1)$ & $144(35.4)$ & $33.3(21.8 \text { to } 44.9)^{c}$ & $18.6(6.8 \text { to } 30.5)^{c}$ & $<.001$ & .001 \\
\hline \multicolumn{8}{|l|}{ DAS28-CRP $\leq 3.2$} \\
\hline No. (\%) & $136(48.3)$ & 137 (37.9) & $128(20.9)$ & $27.4(16.3 \text { to } 38.4)^{\mathrm{b}}$ & $17.0(6.2 \text { to } 27.7)^{b}$ & $<.001$ & .003 \\
\hline \multicolumn{8}{|l|}{ DAS28-CRP $<2.6$} \\
\hline No. (\%) & $136(30.6)$ & $137(26.1)$ & $128(12.2)$ & $18.5(8.6 \text { to } 28.3)^{c}$ & $14.0(4.6 \text { to } 23.4)^{c}$ & $<.001$ & .003 \\
\hline \multicolumn{8}{|l|}{$\begin{array}{l}\text { Functional Assessment } \\
\text { of Chronic Illness } \\
\text { Therapy-Fatigue }\end{array}$} \\
\hline No. & 122 & 110 & 90 & & & & \\
\hline $\begin{array}{l}\text { Mean change from } \\
\text { baseline (SD) }\end{array}$ & $11.6(11.67)$ & $9.8(10.39)$ & $7.0(10.23)$ & $4.6(1.28)^{d}$ & $2.1(1.30)^{d}$ & $<.001$ & .11 \\
\hline \multicolumn{4}{|c|}{$\begin{array}{l}\text { Abbreviations: DAS28-CRP, disease activity score for } 28 \text { joints using C-reactive } \\
\text { protein; HAQ-DI, Health Assessment Questionnaire-Disability Index; } \\
\text { LS, least squares. } \\
\text { a Values are percentage of patients achieving a response unless } \\
\text { otherwise noted. }\end{array}$} & \multicolumn{4}{|c|}{$\begin{array}{l}\text { b } \mathrm{LS} \text { mean difference }(95 \% \mathrm{Cl}) \text {. } \\
\text { c Percentage difference }(95 \% \mathrm{Cl}) \text {. }\end{array}$} \\
\hline
\end{tabular}

Primary and Key Secondary Outcomes

At week 12, the ACR20 response rates (primary end point) were 66.0\% (95\% CI, 58.0\%-74.0\%) and 57.5\% (95\% CI, 49.4\%$65.7 \%$ ) for filgotinib, $200 \mathrm{mg}$ and $100 \mathrm{mg}$, respectively, vs $31.1 \%$ (95\% CI, 23.3\%-38.9\%) for placebo (difference vs placebo: $34.9 \%$ [95\% CI, 23.5\%-46.3\%] for filgotinib, $200 \mathrm{mg}$, and $26.4 \%$ [95\% CI, 15.0\%-37.9\%] for filgotinib, $100 \mathrm{mg}$; both $P<.001$ ). Sensitivity analyses were consistent with these findings and indicate a good model fit.
Table 2 shows key secondary outcomes. The mean (SD) changes in HAQ-DI from baseline to week 12 were - 0.55 (0.59) for filgotinib, $200 \mathrm{mg}$; -0.48 (0.60) for filgotinib, $100 \mathrm{mg}$; and $-0.23(0.55)$ for placebo, with differences vs placebo of -0.32 (95\% CI, -0.45 to -0.19) for filgotinib, $200 \mathrm{mg}$, and -0.27 (95\% CI, -0.40 to -0.14 ) for filgotinib, $100 \mathrm{mg}$ (both $P<.001$ ).

DAS28-CRP of 3.2 or less at week 12 was achieved by more patients taking filgotinib, $200 \mathrm{mg}$ (40.8\% [95\% CI, $32.5 \%-49.1 \%]$ ), and filgotinib, $100 \mathrm{mg}$ (37.3\% [95\% CI, 
29.3\%-45.2\%]), compared with placebo (15.5\% [95\% CI, 9.4\%-21.7\%]) (difference vs placebo: $24.6 \%$ [95\% CI, $14.0 \%$ $35.2 \%$ ] for filgotinib, $200 \mathrm{mg}$, and $21.0 \%$ [95\% CI, 10.7\%$31.4 \%$ ] for filgotinib, $100 \mathrm{mg}$; both $P<.001)$. At week 24 , significant differences between both filgotinib doses and placebo were maintained or improved $(P \leq .001)$. More patients also achieved DAS28-CRP less than 2.6 at week 24 with filgotinib, $200 \mathrm{mg}$ (30.6\% [95\% CI, 22.8\%-38.4\%], difference vs placebo: $18.5 \%$ [95\% CI, 8.6\%-28.3\%]; $P<.001$, and filgotinib, $100 \mathrm{mg}$ (26.1\% [95\% CI, 18.9\%-33.4\%], difference vs placebo: $14.0 \%$ [95\% CI, $4.6 \%-23.4 \%$ ]; $P=.003)$, compared with placebo (12.2\% [95\% CI, 6.6\%-17.8\%]); significant differences from placebo were also observed from week 4 for both doses of filgotinib.

The changes from baseline in 36-Item Short-Form Health Survey Physical Component score at weeks 12 and 24 were significantly greater for both filgotinib doses than for placebo (all $P \leq .002$ vs placebo). Statistically significant effects were seen for improvement in Functional Assessment of Chronic Illness Therapy-Fatigue scores with filgotinib, $200 \mathrm{mg}$ (Table 3).

\section{Other Secondary Outcomes}

ACR20, ACR50, and ACR70 responses over time are shown in Figure 2, A-C. Patients receiving filgotinib had significantly greater improvements in DAS28-CRP over time compared with placebo (Figure 2D). Patients receiving filgotinib had significantly better scores on HAQ-DI and other components of the ACR core set of response criteria (eFigure 3 in Supplement 3). Also, week 12 and week 24 ACR responses, Clinical and Simplified Disease Activity Indexes, and indicators of low disease activity and remission showed the greater efficacy of filgotinib compared with placebo (eTable 3 in Supplement 3).

\section{Subgroup Analyses}

ACR20 responses in patients with 1,2 , and 3 or more prior bDMARDs are shown in eFigure 4 in Supplement 3. This analysis showed that the ACR20 response rates of patients with 3 or more prior bDMARDs at week 12 were $70.3 \%, 58.8 \%$, and $17.6 \%$ for patients receiving filgotinib, $200 \mathrm{mg}$; filgotinib, 100 mg; or placebo, respectively (difference vs placebo: 52.6\% [95\% CI, 30.3\%-75.0\%] for filgotinib, $200 \mathrm{mg}$, and $41.2 \%$ [95\% CI, $17.3 \%-65.0 \%$ ] for filgotinib, $100 \mathrm{mg}$; both $P<.001 \mathrm{vs}$ placebo). eTable 2 in Supplement 3 shows key efficacy and safety data by geographic region.

\section{AEs}

Treatment-emergent AEs were reported in 102 patients (69.4\%) receiving filgotinib, $200 \mathrm{mg}$; 97 (63.4\%) receiving filgotinib, $100 \mathrm{mg}$; and 100 (67.6\%) receiving placebo; 30 (6.7\%) were grade 3 or greater (by Common Terminology Criteria for Adverse Events) in severity. The most frequently reported AEs were nasopharyngitis, upper respiratory tract infection, nausea, bronchitis, and headache (Table 3). Overall, serious AEs occurred in 6 patients (4.1\%) receiving filgotinib, $200 \mathrm{mg} ; 8$ (5.2\%) receiving filgotinib, $100 \mathrm{mg}$; and 5 (3.4\%) receiving placebo. AEs leading to study drug discontinuation were reported in 5 patients (3.4\%) receiving filgotinib, $200 \mathrm{mg}$; 6 (3.9\%) receiving filgotinib, $100 \mathrm{mg}$; and 3 (2.0\%) receiving placebo.
AEs of Special Interest

Infections occurred in 53 patients $(36.1 \%)$ receiving filgotinib, $200 \mathrm{mg}$; 52 patients (34.0\%) receiving filgotinib, $100 \mathrm{mg}$; and 38 patients $(25.7 \%)$ receiving placebo; they were serious in $1(0.7 \%), 3(2.0 \%)$, and $2(1.4 \%)$ patients, in the filgotinib, $200 \mathrm{mg}$; filgotinib, $100 \mathrm{mg}$; and placebo groups, respectively. There were 4 cases of uncomplicated herpes zoster (57- and 62-year-old women with filgotinib, $100 \mathrm{mg}$, and 62- and 63-year-old women with filgotinib, $200 \mathrm{mg}$; all cases were $\leq$ grade 2 in severity). There was 1 report of grade 2 retinal vein occlusion in a 61-year-old man in the filgotinib, $200 \mathrm{mg}$, group, which resolved with 3-monthly doses of intraocular bevacizumab; no other venous thrombotic events were reported. Two major cardiovascular serious AEs (as judged by an independent cardiovascular event adjudication committee) were reported: grade 1 myocardial ischemia in a 61-year-old man in the filgotinib, $100 \mathrm{mg}$, group and grade 2 subarachnoid hemorrhage in a 53-year-old woman in the placebo group. There were no cases of opportunistic infection, active tuberculosis, malignancy, gastrointestinal perforation, or death.

\section{Laboratory Abnormalities}

Table 3 also shows laboratory abnormality treatmentemergent AEs of any grade and grade 3 or higher. The overall frequency of hepatic transaminase elevations ( $>1 \times$ upper limit of normal [ULN]) was higher in the filgotinib groups compared with placebo; however, no grade 3 or 4 increases for alanine aminotransferase and aspartate aminotransferase levels were reported. Most alanine aminotransferase and aspartate aminotransferase elevations were grade 1 or 2 in severity and none coincided with increased bilirubin levels. Three patients in the filgotinib groups (1 [0.7\%] in the filgotinib, $200 \mathrm{mg}$, group and 2 [1.3\%] in the filgotinib, $100 \mathrm{mg}$, group) were reported to have transient increases in alanine aminotransferase and aspartate aminotransferase levels greater than $3 \times$ ULN; none were greater than $5 \times$ ULN. No Hy's law cases (aspartate aminotransferase or alanine aminotransferase $>3 \times$ ULN and total bilirubin $>2 \times \mathrm{ULN}$ ) suggestive of druginduced hepatocellular injury were identified. Transient grade 2 elevations in serum creatinine were reported in 6 patients (4.1\%) receiving filgotinib, $200 \mathrm{mg}$, and 2 patients $(1.4 \%)$ receiving placebo; no patient had a grade 3 or higher increased creatinine laboratory abnormality. Serum creatine kinase levels were increased in both filgotinib groups with grade 3 or 4 elevation reported for $3(2.0 \%)$ in the filgotinib, $100 \mathrm{mg}$, group, $1(0.7 \%)$ in the placebo group, and none in the filgotinib, $200 \mathrm{mg}$, group. Most cases were transient and were not associated with symptoms of muscle toxicity or rhabdomyolysis.

eFigure 5 in Supplement 3 shows mean values for hemoglobin, neutrophils, platelets, and fasting low-density lipoprotein/high-density lipoprotein cholesterol ratio over the course of the study. Mean hemoglobin level changes from baseline were $+0.2 \mathrm{~g} / \mathrm{dL}$ at week 12 with both filgotinib, $200 \mathrm{mg}$ and $100 \mathrm{mg}$, and $-0.1 \mathrm{~g} / \mathrm{dL}$ at week 12 with placebo. AEs of anemia were reported in 4 patients (1.4\% for filgotinib, $200 \mathrm{mg}$, and $1.3 \%$ for filgotinib, $100 \mathrm{mg}$ ) receiving filgotinib vs 4 patients $(2.7 \%)$ receiving placebo. There were no clinically relevant changes in lymphocyte, platelet, and neutrophil counts. 


\begin{tabular}{|c|c|c|c|c|c|c|}
\hline \multirow[b]{3}{*}{ Safety Data } & \multicolumn{6}{|l|}{ №. (\%) } \\
\hline & \multicolumn{3}{|l|}{ Weeks 0-12 } & \multicolumn{3}{|l|}{ Weeks 0-24 } \\
\hline & $\begin{array}{l}\text { Filgotinib, } 200 \mathrm{mg} \\
(\mathrm{n}=147)\end{array}$ & $\begin{array}{l}\text { Filgotinib, } 100 \mathrm{mg} \\
(\mathrm{n}=153)\end{array}$ & $\begin{array}{l}\text { Placebo } \\
(\mathrm{n}=148)\end{array}$ & $\begin{array}{l}\text { Filgotinib, } 200 \mathrm{mg} \\
(\mathrm{n}=147)\end{array}$ & $\begin{array}{l}\text { Filgotinib, } 100 \mathrm{mg} \\
(\mathrm{n}=153)\end{array}$ & $\begin{array}{l}\text { Placebo } \\
(\mathrm{n}=148)\end{array}$ \\
\hline Treatment-emergent adverse events & $82(55.8)$ & $77(50.3)$ & $80(54.1)$ & $102(69.4)$ & $97(63.4)$ & $100(67.6)$ \\
\hline \multicolumn{7}{|l|}{$\begin{array}{l}\text { Most common treatment-emergent } \\
\text { adverse events (occurring in } \\
>5 \% \text { of patients) }\end{array}$} \\
\hline Nasopharyngitis & $9(6.1)$ & $5(3.3)$ & $4(2.7)$ & $15(10.2)$ & $9(5.9)$ & $7(4.7)$ \\
\hline Upper respiratory tract infection & $6(4.1)$ & $3(2.0)$ & $5(3.4)$ & $8(5.4)$ & $9(5.9)$ & $6(4.1)$ \\
\hline Headache & $7(4.8)$ & $6(3.9)$ & $2(1.4)$ & $8(5.4)$ & $9(5.9)$ & $2(1.4)$ \\
\hline Bronchitis & $5(3.4)$ & 0 & $7(4.7)$ & $8(5.4)$ & $3(2.0)$ & $8(5.4)$ \\
\hline Nausea & $7(4.8)$ & $7(4.6)$ & $4(2.7)$ & $7(4.8)$ & $8(5.2)$ & $6(4.1)$ \\
\hline Serious adverse events ${ }^{\mathrm{b}}$ & $4(2.7)$ & $6(3.9)$ & $4(2.7)$ & $6(4.1)$ & $8(5.2)$ & $5(3.4)$ \\
\hline $\begin{array}{l}\text { Discontinued study drug because of } \\
\text { treatment-emergent adverse event }\end{array}$ & $4(2.7)$ & $6(3.9)$ & $3(2.0)$ & $5(3.4)$ & $6(3.9)$ & $3(2.0)$ \\
\hline Death & 0 & 0 & 0 & 0 & 0 & 0 \\
\hline \multicolumn{7}{|l|}{$\begin{array}{l}\text { Treatment-emergent adverse events } \\
\text { of interest }\end{array}$} \\
\hline Infection & $34(23.1)$ & $29(19.0)$ & $27(18.2)$ & $53(36.1)$ & $52(34.0)$ & $38(25.7)$ \\
\hline Herpes zoster (uncomplicated) & $1(0.7)$ & $2(1.3)$ & 0 & $2(1.4)$ & $2(1.3)$ & 0 \\
\hline \multicolumn{7}{|l|}{ Safety data } \\
\hline Active tuberculosis & 0 & 0 & 0 & 0 & 0 & 0 \\
\hline Opportunistic infection & 0 & 0 & 0 & 0 & 0 & 0 \\
\hline Serious infection ${ }^{c}$ & $1(0.7)$ & $1(0.7)$ & $2(1.4)$ & $1(0.7)$ & $3(2.0)$ & $2(1.4)$ \\
\hline Venous thrombotic events & $1(0.7)^{c}$ & 0 & 0 & $1(0.7)^{d}$ & 0 & 0 \\
\hline $\begin{array}{l}\text { Malignancy (excluding nonmelanoma } \\
\text { skin cancer) }\end{array}$ & 0 & 0 & 0 & 0 & 0 & 0 \\
\hline Nonmelanoma skin cancer & 0 & 0 & 0 & 0 & 0 & 0 \\
\hline $\begin{array}{l}\text { Major adverse cardiovascular event } \\
\text { (adjudicated) }^{\mathrm{e}}\end{array}$ & 0 & $1(0.7)$ & $1(0.7)$ & 0 & $1(0.7)^{f}$ & $1(0.7)^{g}$ \\
\hline \multirow[t]{2}{*}{ Gastrointestinal perforation } & 0 & 0 & 0 & 0 & 0 & 0 \\
\hline & \multicolumn{3}{|l|}{ Week 0-24 Any Grade } & \multicolumn{3}{|c|}{ Week $0-24$ Grade 3 or $4^{\mathrm{h}}$} \\
\hline \multicolumn{7}{|l|}{ Laboratory Abnormalities } \\
\hline \multicolumn{7}{|l|}{ Decreased } \\
\hline Hemoglobin & $28(19.0)$ & $24(15.7)$ & $43(29.1)$ & $1(0.7)$ & $1(0.7)$ & $2(1.4)$ \\
\hline Neutrophil count & $17(11.6)$ & $8(5.2)$ & $7(4.7)$ & $2(1.4)$ & 0 & $1(0.7)$ \\
\hline Lymphocyte count & $21(14.3)$ & $11(7.2)$ & $19(12.8)$ & $4(2.7)$ & $1(0.7)^{g}$ & $3(2.0)$ \\
\hline Platelet count & $1(0.7)$ & $1(0.7)$ & $4(2.7)$ & 0 & 0 & 0 \\
\hline \multicolumn{7}{|l|}{ Increased } \\
\hline Alanine aminotransferase & $34(23.1)$ & $30(19.6)$ & $21(14.2)$ & 0 & 0 & 0 \\
\hline Aspartate aminotransferase & $38(25.9)$ & $30(19.6)$ & $18(12.2)$ & 0 & 0 & 0 \\
\hline Creatinine & $12(8.2)$ & $4(2.6)$ & $3(2.0)$ & 0 & 0 & 0 \\
\hline Creatine kinase & $43(29.3)$ & $22(14.4)$ & $16(10.8)$ & 0 & $3(2.0)^{h}$ & $1(0.7)$ \\
\hline \multicolumn{3}{|c|}{$\begin{array}{l}\text { Week } 0 \text { to } 24 \text { data include events that began on or after the study drug start } \\
\text { date up to } 30 \text { days after permanent discontinuation of study drug or that led } \\
\text { to premature study drug discontinuation. }\end{array}$} & \multicolumn{4}{|c|}{$\begin{array}{l}\text { c Serious infectious adverse events were defined as all patients in the infections } \\
\text { and infestations System Organ Class that were serious adverse events. } \\
{ }^{d} \text { Retinal vein thrombosis. }\end{array}$} \\
\hline \multicolumn{3}{|c|}{$\begin{array}{l}\text { b At week 24, serious adverse events in the filgotinib, } 200 \text { mg, group included } \\
1 \text { case each of dehydration, bursitis, cellulitis, concussion, diarrhea, laceration, } \\
\text { lactic acidosis, pulmonary edema, rib fracture, uterine hemorrhage, and } \\
\text { vertigo; in the filgotinib, } 100 \text { mg, group } 1 \text { case each of oral abscess, anemia, } \\
\text { bronchitis, depression, gallbladder empyema, lumbar spinal stenosis, } \\
\text { myocardial ischemia, osteitis, and vulval abscess; and in the placebo group } \\
2 \text { cases of gastroenteritis and } 1 \text { case each of dehydration, chest pain, dyspnea, } \\
\text { hyponatremia, lumbar vertebral fracture, nausea, rheumatoid arthritis, } \\
\text { subarachnoid hemorrhage, systemic inflammatory response syndrome, } \\
\text { and vomiting. }\end{array}$} & $\begin{array}{l}\text { h All laboratory abnormalities reported were grade } 3 \text { except } 1 \text { patient }(0.7 \%) \\
\text { experienced a grade } 4 \text { decrease in lymphocyte count and } 1 \text { (0.7\%) } \\
\text { experienced a grade } 4 \text { increase in creatine kinase. }\end{array}$ & $\begin{array}{l}\text { ted major adverse car } \\
\text { rdiovascular safety en } \\
\text { ia. } \\
\text { orrhage. } \\
\text { e } 4 \text { decrease in lympl } \\
\text { le } 4 \text { increase in creatir }\end{array}$ & $\begin{array}{l}\text { ovascular events as as } \\
\text { point adjudication co } \\
\text { grade } 3 \text { except } 1 \text { pati } \\
\text { cyte count and } 1 \text { ( } 0.7 \\
\text { kinase. }\end{array}$ & $\begin{array}{l}\text { essed by } \\
\text { mittee. } \\
\text { t }(0.7 \%)\end{array}$ \\
\hline
\end{tabular}

(C) 2019 American Medical Association. All rights reserved. 


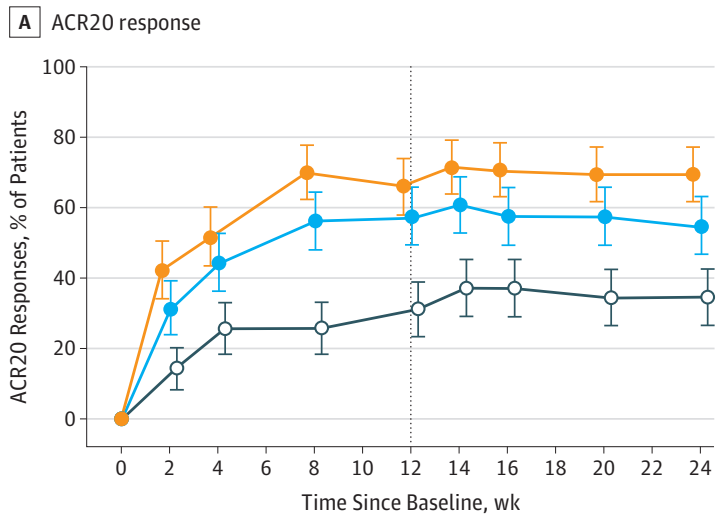

No. at risk

$\begin{array}{llllllllllll}\text { Filgotinib, } 200 \mathrm{mg} & 147 & 147 & 147 & 147 & 147 & 147 & 147 & 147 & 147\end{array}$

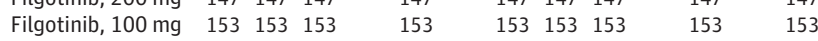
$\begin{array}{lllllllllll}\text { Placebo } & 148 & 148 & 148 & 148 & 148 & 148 & 148 & 148 & 148\end{array}$

C ACR70 response

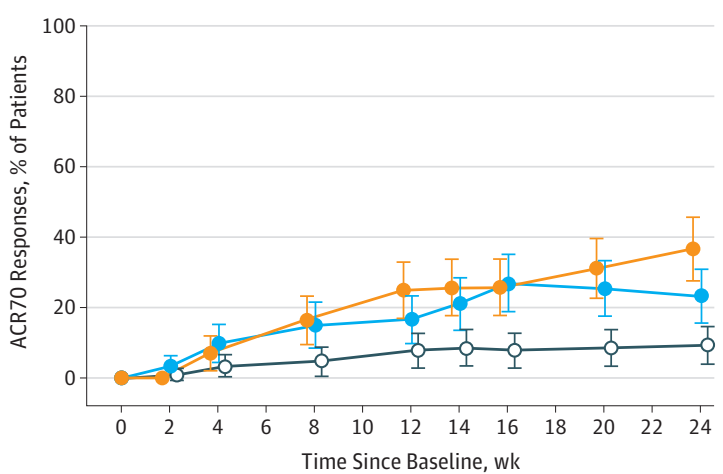

No. at risk

$\begin{array}{lllllllllll}\text { Filgotinib, } 200 \mathrm{mg} & 147 & 147 & 147 & 147 & 147 & 147 & 147 & 147 & 147\end{array}$

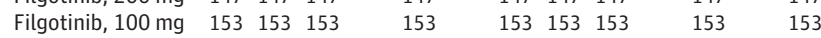

$\begin{array}{llllllllll}\text { Placebo } & 148 & 148 & 148 & 148 & 148 & 148 & 148 & 148 & 148\end{array}$
B ACR50 response

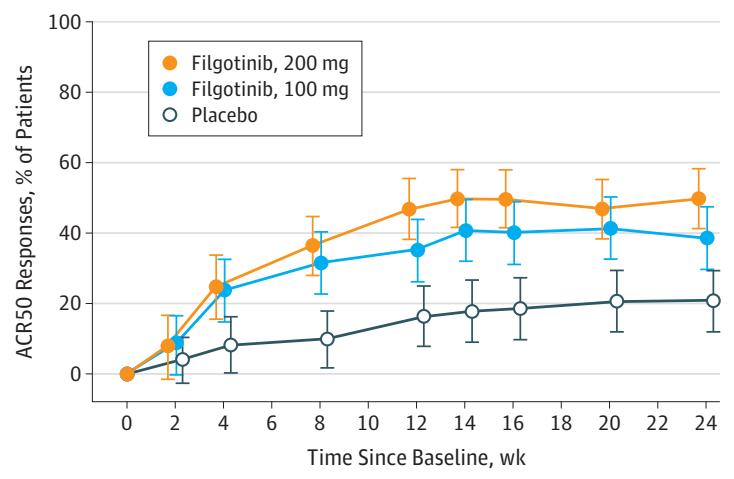

$\begin{array}{lll}147 & 147 \quad 147\end{array}$

$\begin{array}{llll}147 & 147 & 147 & 147\end{array}$

$\begin{array}{lllllll}148 & 148 & 148 & 153 & 153 & 153 & 153 \\ & 148 & 148 & 148 & 148\end{array}$

$147 \quad 147$

D DAS28-CRP score

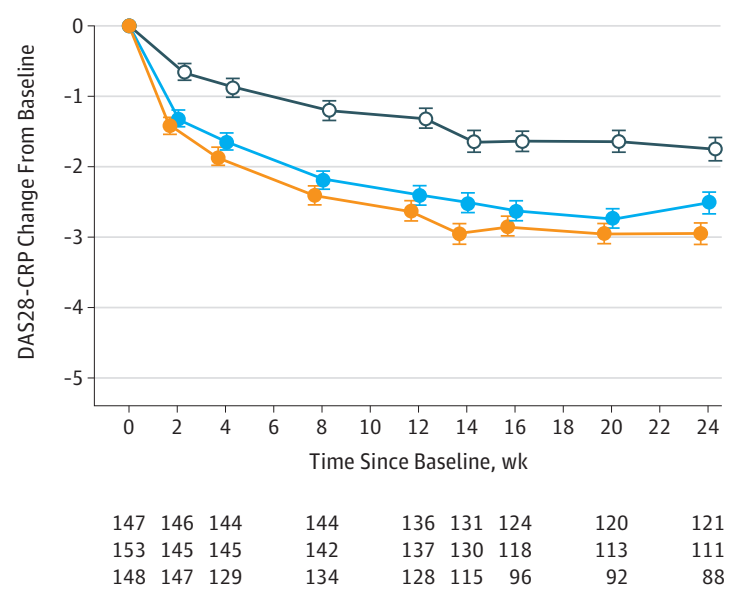

Panels $A, B$, and $C$ show the percentage of patients who had $20 \%$ improvement in American College of Rheumatology criteria (ACR20), 50\% improvement (ACR50), and 70\% improvement (ACR70), respectively, with nonresponder imputation. The vertical line in panel $A$ at 12 weeks indicates the primary efficacy time point. Panel $D$ shows the least square mean change from baseline in the 28-joint disease activity score based on the level of disease activity score in 28 joints using C-reactive protein (DAS28-CRP). A mixed-effects model with repeated measures was used to evaluate treatment effect on change from baseline with treatment, visit, treatment-by-visit interaction, stratification factors, and baseline value included in the model as fixed effects and patient as a random effect. No imputation was used for change from baseline data that were missing. In panels A and D, filgotinib, $200 \mathrm{mg}$, and filgotinib, $100 \mathrm{mg}$, vs placebo were significant $(P \leq .001)$ at all postbaseline time points. In panel $\mathrm{B}$, postbaseline time points were significant $(P \leq .01)$, with the exception of filgotinib, $200 \mathrm{mg}$, and filgotinib, $100 \mathrm{mg}$, at week $2(P>.05)$. In panel $C$, postbaseline time points were significant $(P \leq .01)$, with the exception of filgotinib, $200 \mathrm{mg}$, and filgotinib, $100 \mathrm{mg}$, at week $2(P>$.05); filgotinib, $200 \mathrm{mg}$, at week $4(P>.05)$; and filgotinib, $100 \mathrm{mg}$, at weeks 4 and $12(P \leq .05)$.

\section{Discussion}

Once-daily filgotinib, $200 \mathrm{mg}$ or $100 \mathrm{mg}$, in the setting of concurrent csDMARD use met the primary end point of difference vs placebo on ACR 20 at week 12 . All hierarchically tested secondary end points (ACR response, DAS28-CRP, Simplified Disease Activity Index, Clinical Disease Activity Index, and individual ACR core set parameters) demonstrated significant improvements vs placebo in patients who had active RA despite prior bDMARD therapy.

Similar treatment-refractory patient populations have previously been evaluated in other phase 3 trials of JAK inhibitors (upadacitinib, ${ }^{21}$ baricitinib, ${ }^{22}$ and tofacitinib ${ }^{23}$ ). The ACR20 response rates at week 12 in these trials were as follows: upadacitinib, $30 \mathrm{mg}$, 65\%; baricitinib, $4 \mathrm{mg}$, 55\%; and tofacitinib, $5 \mathrm{mg}, 42 \%$, compared with filgotinib, $200 \mathrm{mg}, 66 \% .^{21-23}$ Improvements in ACR20 with filgotinib were evident at week 2 (earliest assessment), and responses were maintained or improved over 24 weeks, reflecting a time course similar to that seen with other JAK inhibitors. ${ }^{21-23}$ The proportions of patients achieving DAS28-CRP of 3.2 or less at week 12 in these studies showed a similar trend: upadacitinib, $30 \mathrm{mg}$, 42\%; baricitinib, $4 \mathrm{mg}$, 31\%; and tofacitinib, $5 \mathrm{mg}$, 21\%, compared with filgotinib, $200 \mathrm{mg}, 41 \% .^{21-23}$ At week $24,30.6 \%$ of patients treated with filgotinib, $200 \mathrm{mg}$, achieved disease 
remission (DAS28-CRP <2.6). Responses with the filgotinib, 200-mg, dose were numerically higher compared with the 100-mg dose, but no statistical analysis for potential dose response was done.

For patients with active RA refractory to bDMARDs, subsequent treatment has generally been observed to be less effective, especially as the number of previous treatments increases. ${ }^{22,24}$ In this study, patient randomization was stratified based on the number of previous bDMARDs and the analysis was prespecified to examine the number of prior treatments. ACR2O response rates with filgotinib were independent of the number of prior bDMARDs; the ACR20 response rates to filgotinib, $200 \mathrm{mg}$ and $100 \mathrm{mg}$, were $70.3 \%$ and $58.8 \%$, respectively, in patients previously treated with 3 or more bDMARDs, while that of the overall population was $66 \%$ and $57.5 \%$, respectively. These results are similar to the response rates in filgotinib phase 2 studies, which mainly enrolled patients who were naive to bDMARDs. ${ }^{8,9}$ The response rates for patients taking placebo (background csDMARDs only) did decrease as expected with the number of prior bDMARDs, suggesting that the consistent efficacy of filgotinib in these patients is not an artifactual finding.

This study was not powered to make statistical comparisons of adverse events among the randomized groups, which limits the interpretation of these findings. There was little difference in the proportion of adverse events between treatment groups, and most were grade 1 or 2 in severity. Few patients in any treatment group discontinued study drugs due to an AE. AEs reported with other JAK inhibitors were rare, including serious infectious $\mathrm{AEs}(\leq 2 \%$ in the filgotinib groups), major adverse cardiovascular events (1 each in the filgotinib, $100 \mathrm{mg}$, and placebo groups), and $1 \mathrm{AE}$ of retinal vein occlusion (which did not result in an interruption of filgotinib treatment and resolved with bevacizumab treatment). Infections occurred in 35\% of filgotinib-treated patients (with similar event rates at both filgotinib doses) and $26 \%$ of placebo-treated patients. There were no opportunistic infections, active tuberculosis, malignancies, gastrointestinal perforations, or deaths. Laboratory abnormality AEs were reported at similar frequencies across all groups and there were no clinically relevant changes from baseline in mean values for hematology. Mostly mild increases in creatine kinase and transaminases in the filgotinib groups were observed; however, elevations greater than $\times 3$ ULN were infrequent. Similar to the other JAK inhibitors, transient and symptomatic increases in creatine kinase values were more common in the filgotinib groups; however, they did not require any intervention.

\section{Limitations}

This study has several limitations. First, the 24-week duration precludes conclusions regarding longer-term safety and duration of benefit. Second, there were no radiographic end points to evaluate structural joint damage. Third, the study population was limited to the more refractory group of patients who continue to have active disease despite prior bDMARD therapy. Fourth, this trial was conducted primarily in patients from North America and Western Europe; thus, the ability to translate these data to additional populations remains a focus for future study. AEs, efficacy, and radiographic end points in other patient populations are being evaluated in multinational phase 3 trials of filgotinib (FINCH 1 [methotrexate-inadequate responders, NCTO2889796] and FINCH 3 [methotrexate-naive patients, NCTO2886728]). Fifth, the trial was limited in duration and not powered to study safety. Therefore, additional analyses will be needed across different RA populations over the longer term to better define the safety profile of filgotinib, and an extension trial (FINCH 4, NCT03025308) is being conducted to evaluate the long-term outcomes of patients who completed the FINCH studies.

\section{Conclusions}

Among patients with active RA who had an inadequate response or intolerance to 1 or more bDMARDs, filgotinib, 100 mg or $200 \mathrm{mg}$ daily, compared with placebo resulted in a significantly greater proportion achieving a clinical response at week 12. However, further research is needed to assess longerterm efficacy and safety.

\section{ARTICLE INFORMATION}

Accepted for Publication: June 6, 2019.

Correction: This article was corrected online on February 4, 2020, to fix demographic data reported in Table 1 and disease characteristic data reported in eTable 2 in Supplement 3.

Author Affiliations: Division of Immunology and Rheumatology, Stanford University, Stanford, California (Genovese); Division of Rheumatology, Allergy, and Immunology, University of California, San Diego, La Jolla (Kalunian); Department of Rheumatology, Strasbourg University Hospital, Strasbourg, France (Gottenberg); Gilead Sciences Inc, Foster City, California (Mozaffarian, Bartok, Matzkies, Gao, Guo, Sundy); Galapagos NV, Mechelen, Belgium (Tasset); Department of Rheumatology, Universitair Ziekenhuis Leuven, Leuven, Belgium (de Vlam); Northumbria Healthcare, North Shields, United Kingdom (Walker);
Division of Rheumatology, Keio University School of Medicine, Tokyo, Japan (Takeuchi).

Author Contributions: Dr Genovese had full access to all of the data in the study and takes responsibility for the integrity of the data and the accuracy of the data analysis.

Concept and design: Genovese, Mozaffarian, Matzkies, Tasset, Sundy, Takeuchi.

Acquisition, analysis, or interpretation of data: Genovese, Kalunian, Gottenberg, Mozaffarian, Bartok, Matzkies, Gao, Guo, Tasset, Sundy, de Vlam, Walker.

Drafting of the manuscript: Genovese, Bartok, Matzkies, Sundy, Walker.

Critical revision of the manuscript for important intellectual content: All authors.

Statistical analysis: Matzkies, Gao, Guo.

Obtained funding: Genovese, Matzkies.

Administrative, technical, or material support:

Genovese, Kalunian, Matzkies, Sundy.
Supervision: Genovese, Gottenberg, Mozaffarian, Bartok, Matzkies, Sundy, de Vlam, Takeuchi.

Conflict of Interest Disclosures: Dr Genovese reported receiving grants and personal fees from Gilead and grants from Galapagos during the conduct of the study and grants and personal fees from Lilly, AbbVie, Pfizer, Astellas, Vertex, Sanofi, EMD Serono, and Genentech/Roche and personal fees from Incyte outside the submitted work. Dr Kalunian reported receiving grants from Gilead during the conduct of the study. Dr Gottenberg reported receiving personal fees from AbbVie, Pfizer, UCB, Eli Lilly, and Sanofi-Genzyme; grants and personal fees from Bristol-Myers Squibb; and nonfinancial support from Roche outside the submitted work. Drs Mozaffarian, Bartok, Matzkies, Gao, Guo, and Sundy are employees and stockholders of Gilead Sciences. Dr Tasset is an employee and stockholder of Galapagos NV. Dr Walker reported serving on advisory boards and 
speaking at meetings for Eli Lilly, Pfizer, Novartis, and Gilead. Dr Takeuchi reported receiving grants and personal fees from AbbVie, Astellas Pharma Inc, Chugai Pharmaceutical Co Ltd, Daiichi Sankyo Co, Eisai Co Ltd, Mitsubishi Tanabe Pharma Co, Nipponkayaku Co Ltd, Pfizer Japan Inc, and Takeda Pharmaceutical Co Ltd; personal fees from AstraZeneca, Bristol-Myers Squibb, Eli Lilly Japan, GlaxoSmithKline, Janssen Pharmaceutical, Novartis Pharma, AYUMI Pharmaceutical Corporation, Sanofi, Teijin Pharma Ltd, Taiho Pharmaceutical Co Ltd, Taisho Pharmaceutical Co Ltd, and UCB Japan Co Ltd; and grants from Asahikasei Pharma Corp during the conduct of the study. No other disclosures were reported.

Funding/Support: This study was supported by Gilead Sciences Inc.

Role of the Funder/Sponsor: The trial was designed by Gilead Sciences Inc in collaboration with academic advisors; Gilead had an oversight role in the conduct of the study and collection, analysis, and interpretation of the data; and Gilead employee authors were involved in the preparation, review, and approval of the manuscript and the decision to submit the manuscript for publication. Gilead did not have the right to veto publication or to control the decision regarding to which journal the article was submitted.

Additional Contributions: We thank all of the patients, their families, and the FINCH investigators/site staff. Assistance with manuscript preparation, development of tables and figures, and process support was provided by Beth Sesler, $\mathrm{PhD}, \mathrm{CMPP}$, at Impact Communications and funded by Gilead Sciences Inc.

Data Sharing Statement: See Supplement 4

\section{REFERENCES}

1. Singh JA, Saag KG, Bridges SL Jr, et al; American College of Rheumatology. 2015 American College of Rheumatology guideline for the treatment of rheumatoid arthritis. Arthritis Care Res (Hoboken). 2016;68(1):1-25. doi:10.1002/acr.22783

2. Smolen JS, Landewé R, Breedveld FC, et al. EULAR recommendations for the management of rheumatoid arthritis with synthetic and biological disease-modifying antirheumatic drugs: 2013 update. Ann Rheum Dis. 2014;73(3):492-509. doi: 10.1136/annrheumdis-2013-204573

3. Kalden JR, Schulze-Koops H. Immunogenicity and loss of response to TNF inhibitors: implications for rheumatoid arthritis treatment. Nat Rev Rheumatol. 2017;13(12):707-718. doi:10.1038/ nrrheum.2017.187

4. Banerjee S, Biehl A, Gadina M, Hasni S, Schwartz DM. JAK-STAT signaling as a target for inflammatory and autoimmune diseases: current and future prospects. Drugs. 2017;77(5):521-546. doi:10.1007/s40265-017-0701-9

5. Walker JG, Smith MD. The Jak-STAT pathway in rheumatoid arthritis. J Rheumatol. 2005;32(9): 1650-1653.

6. Brennan FM, McInnes IB. Evidence that cytokines play a role in rheumatoid arthritis. J Clin Invest. 2008;118(11):3537-3545. doi:10.1172/JCI36389

7. Van Rompaey L, Galien R, van der Aar EM, et al. Preclinical characterization of GLPG0634, a selective inhibitor of JAK1, for the treatment of inflammatory diseases. J Immunol. 2013;191(7): 3568-3577. doi:10.4049/jimmunol.1201348

8. Kavanaugh A, Kremer J, Ponce L, et al. Filgotinib (GLPG0634/GS-6034), an oral selective JAK1 inhibitor, is effective as monotherapy in patients with active rheumatoid arthritis: results from a randomised, dose-finding study (DARWIN 2). Ann Rheum Dis. 2017;76(6):1009-1019. doi:10.1136/ annrheumdis-2016-210105

9. Westhovens R, Taylor PC, Alten R, et al. Filgotinib (GLPG0634/GS-6034), an oral JAK1 selective inhibitor, is effective in combination with methotrexate (MTX) in patients with active rheumatoid arthritis and insufficient response to MTX: results from a randomised, dose-finding study (DARWIN 1). Ann Rheum Dis. 2017;76(6):9981008. doi:10.1136/annrheumdis-2016-210104

10. Aletaha D, Neogi T, Silman AJ, et al. 2010 Rheumatoid arthritis classification criteria: an American College of Rheumatology/European League Against Rheumatism collaborative initiative. Arthritis Rheum. 2010;62(9):2569-2581. doi:10. 1002/art.27584

11. Felson DT, Anderson JJ, Boers M, et al. American College of Rheumatology preliminary definition of improvement in rheumatoid arthritis. Arthritis Rheum. 1995;38(6):727-735. doi:10.1002/art.1780380602

12. Disease Activity Score in rheumatoid arthritis. https://www.das-score.nl/das28/en/introductionmenu.html. Accessed January 15, 2019.

13. Prevoo ML, van 't Hof MA, Kuper $\mathrm{HH}$ van Leeuwen MA, van de Putte LB, van Riel PL. Modified disease activity scores that include twenty-eight-joint counts: development and validation in a prospective longitudinal study of patients with rheumatoid arthritis. Arthritis Rheum. 1995;38(1):44-48. doi:10.1002/art.1780380107

14. Fries JF, Spitz P, Kraines RG, Holman HR. Measurement of patient outcome in arthritis. Arthritis Rheum. 1980;23(2):137-145. doi:10.1002/ art.1780230202

15. Fries JF, Spitz PW, Young DY. The dimensions of health outcomes: the health assessment questionnaire, disability and pain scales. J Rheumatol. 1982;9(5):789-793.

16. Ware JE Jr, Sherbourne CD. The MOS 36 -item short-form health survey (SF-36), I: conceptual framework and item selection. Med Care. 1992;30 (6):473-483. doi:10.1097/00005650-19920600000002

17. Webster K, Cella D, Yost K. The Functional Assessment of Chronic Illness Therapy (FACIT) measurement system: properties, applications, and interpretation. Health Qual Life Outcomes. 2003;1:79. doi:10.1186/1477-7525-1-79

18. Aletaha D, Nell VP, Stamm T, et al. Acute phase reactants add little to composite disease activity indices for rheumatoid arthritis: validation of a clinical activity score. Arthritis Res Ther. 2005;7(4): R796-R806. doi:10.1186/ar1740

19. Aletaha D, Smolen J. The Simplified Disease Activity Index (SDAI) and the Clinical Disease Activity Index (CDAI): a review of their usefulness and validity in rheumatoid arthritis. Clin Exp Rheumatol. 2005;23(5)(suppl 39):S100-S108.

20. Smolen JS, Breedveld FC, Schiff MH, et al. A simplified disease activity index for rheumatoid arthritis for use in clinical practice. Rheumatology (Oxford). 2003;42(2):244-257. doi:10.1093/ rheumatology/keg072

21. Genovese MC, Fleischmann R, Combe B, et al. Safety and efficacy of upadacitinib in patients with active rheumatoid arthritis refractory to biologic disease-modifying anti-rheumatic drugs (SELECT-BEYOND): a double-blind, randomised controlled phase 3 trial. Lancet. 2018;391(10139): 2513-2524. doi:10.1016/S0140-6736(18)31116-4

22. Genovese MC, Kremer J, Zamani O, et al. Baricitinib in patients with refractory rheumatoid arthritis. N Engl J Med. 2016;374(13):1243-1252. doi: 10.1056/NEJMoa1507247

23. Burmester GR, Blanco R, Charles-Schoeman C, et al; ORAL Step investigators. Tofacitinib (CP-690,550) in combination with methotrexate in patients with active rheumatoid arthritis with an inadequate response to tumour necrosis factor inhibitors: a randomised phase 3 trial. Lancet. 2013; 381(9865):451-460. doi:10.1016/S0140-6736(12) 61424-X

24. Rendas-Baum R, Wallenstein GV, Koncz T, et al. Evaluating the efficacy of sequential biologic therapies for rheumatoid arthritis patients with an inadequate response to tumor necrosis factor-a inhibitors. Arthritis Res Ther. 2011;13(1):R25. doi:10. 1186/ar3249 